\title{
Determination of fracture toughness in plain concrete specimens by $R$ curve
}

\author{
Chbani Hamza, Saadouki Bouchra \\ Laboratory of Control and Mechanical Characterization of Materials and Structures, National Higher School of Electricity and \\ Mechanics, BP 8118 Oasis, Hassan II, Morocco \\ Boudlal Mostapha, Barakat Mohamed \\ Laboratory of Mechanics Higher Institute of Maritimes 'Studies (ISEM), Km 7 Road El Jadida - Casablanca, Morocco
}

\begin{abstract}
Experimental tests and computational algorithm are implemented to investigate crack growth phenomena in C0.7 concrete. Firstly, three point bending tests are carried out on normalized prismatic specimens notched laterally (SENB), then, computational calculation was developed to calculate the concrete toughness on the basis of R-curve method. The R-curve was obtained from the curve connecting the crack mouth opening displacement (CMOD) to the applied load. During loading, elastic deformation followed by a significant plastic deformation were observed. Therefore, the crack growth in C0.7 concrete is defining by three stages: crack initiation, stable crack propagation and an unstable fracture. The average value of the critical stress intensity factor for the $\mathrm{C} 0.7$ concrete is $1.05 \mathrm{MPa} \cdot \mathrm{m}^{1 / 2}$.
\end{abstract}

KEYwORDS. Toughness, R-curve, CMOD, SENB, Three-point bending

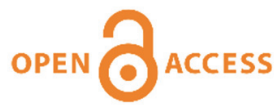

Citation: Chbani, H., Saadouki, B., Boudlal, M., Barakat, M., Determination of fracture toughness in plain concrete specimens by $\mathrm{R}$ curve, Frattura ed Integrità Strutturale, 49 (2019) 763-774.

Received: 13.05 .2019

Accepted: 19.06.2019

Published: 01.07.2019

Copyright: (C) 2019 This is an open access article under the terms of the CC-BY 4.0, which permits unrestricted use, distribution, and reproduction in any medium, provided the original author and source are credited.

\section{INTRODUCTION}

$\mathrm{C}$ oncrete is one of the most used construction materials in Morocco, just like in the rest of the world. The main benefits of this material are the low cost of production compared to other Civil Engineering materials, its secular durability and its elaboration which is relatively simple as it gives the availability of primary natural materials. It is therefore for economic and technical reasons that concrete has become irreplaceable in the construction domain. Much of immense structures such as nuclear center, dams and bridges undergoes an aging and requires particular attention to ensure their maintenance and safety.

Innovative and large sizes structures are built of concrete such as nuclear power plants, dams and bridges, which encourages researchers to focus more on investigations related to this material. Structural calculations performed by technical offices are based on the classical mechanical characteristics (yield strength, compressive strength, bending strength...); the builder chooses the type of concrete to realize its structure from the data provided by the technical office. Under certain stress conditions a defect even of very small dimensions can lead to sudden failure. Faced with the impossibility of structures calculating from the results of the brittle failure [1], it seemed fundamental to predict the critical dimensions of the defects that, under given stress conditions, caused catastrophic failures. This led to the introduction of 
a certain characteristic of the material toughness « fracture toughness » characterizing the ability of a material to resist the sudden crack propagation.

However, concrete structures are complex systems that can represent significant damage. The fracture mechanism of concrete can be similar to that produced in composite systems [2-4], these studies have used analytical formulation and developed computational methods based on FEM approach in order to predict crack growth and failure scenarios in structural and mechanical systems. In the current work, concrete was considered as a homogeneous material but a calculation algorithm by computational tool was required besides experimental tests to determine the concrete toughness. The stress intensity factor $\mathrm{K}_{\mathrm{IC}}$ is an important parameter for the characterization of brittle and quasi- brittle materials when they contain cracks. In order to perform an accurate analysis of materials fracture, the measurement of strength at failure by laboratory tests is essential. Several tests have been adopted in this sense, we quote the most used: Single Edge Pre-cracked Beam (SEPB), Chevron Notched Beam (CNB) and surface crack in flexure and indentation methods [5-8]. These prototypes are all based on three or four point bending test, but they use different forms of notches, with different adjustment and calculation of stress intensity factor methods.

The study of the cracking mechanism in the case of brittle and quasi- brittle materials has been investigated in several studies research. The common aim of all this work is to determine the R curve; the test used is often the three-point bending test, but the employed techniques for tenacity determination change from one paper research to another. Graziani et al [9] determined the curve R of material clay using the Digital Image Correlation technique (DIC), they confirmed the effectiveness of the optical technique in the acquisition of experimental parameters CMOD, CTOD, and delta (a). Another technique based on the analytical resolution of the Euler equation was also adopted in [10], this technique does not require the measurement of the crack length and uses only the initial and the failure concrete energies. The finite element method was also developed by Alam et al [11] for the concrete toughness calculation; they concluded that the toughness value is affected by the aggregate change. Kumar et al [12] used the 3-parameter $\mathrm{R}$ curve to predict the critical load of concrete. However, the experimental measurement of CMOD remains the most common technique for concrete toughness measurement; the R-curve is established directly from the experimental load-CMOD curve. Thus, the toughness is defined by the asymptotic limit of the R-curve [13,14]. Shilang xu et al $[15,16]$ have investigated crack growth in concrete using double-K criterion. In their work, laser speckle interferometry on small size three-point bending notched beams was used in order to predict the crack propagation during the fracture process in quasi-brittle materials. Their investigation defined the critical stress intensity factor for each crack propagation stage.

In this work, we have been interested in the B25 concrete study, for this reason we have used the Single Edge Pre-cracked Beam (SEPB) as it gives reliable $\mathrm{K}_{\mathrm{IC}}$ values, especially in the case of a brittle material in which the linear mechanic of fracture can be applied [14], this method is summarized in a prismatic specimen with a notch, mounted on a three-point bending test bench. An adequate assembly was put in place to measure the crack opening each moment of the test until the material failure. This allows us to predict the crack evolution the: stopping the propagation, stable propagation, or unstable propagation and specimen failure. Indeed, we obtained the R-Curve in which the strength failure is measured according to the crack length using the CMOD.

\section{MATERIAL AND METHODS}

\section{Material}

7 he standard NF EN 206-1 specifies five types of reference concretes, defined by the maximum size of aggregates and the proportions of the mixture. The reference concrete is chosen according to the type of product, the system of protection and repair of concrete structures, and also according to the standards of associated test methods.

Given the importance of concrete in the construction domain, we have chosen for this study the most used concrete type which is the ordinary concrete of the reference C 0.7 known by the trade name B25. The studied concrete is formulated for 28 days to have a simple compressive strength of the order of $25 \mathrm{MPa}$ for cylindrical specimens and $30 \mathrm{MPa}$ for cubic specimens. About the workability of this concrete type in the fresh state which is characterized, inter alia, by the cone of Abrams slump value, the formulation is established for a plastic concrete with the slump of the order of $18 \mathrm{~cm}$.

Tab. 1 gives the different constituents dosage (aggregates, cement, water and admixture) of the C 0.7 type concrete.

\section{Material characterization}

Several experimental techniques allow to characterize physically and mechanically the concrete. In this study we measured slump, porosity, density, compressive strength and bending strength. Tab. 2 represent the different results found at the age of 28 days. 


\begin{tabular}{cc}
\hline Concrete constituents & Weight in $\mathrm{Kg} / \mathrm{m}^{3}$ \\
Sand 0/4 & 1026 \\
Aggregate $1 \quad 4 / 10$ & 611 \\
Aggregate $2 \quad 12 / 16$ & 335 \\
water & 192 \\
Cement CPJ 55 MPa & 275 \\
admixture & 2.475 \\
\hline
\end{tabular}

Table 1: C 0.7 concrete constituents

\begin{tabular}{l} 
slump \\
Porosity \\
Volume weight \\
Young's modulus E \\
Compressive strength for cylindrical specimens \\
Compressive strength for cubic specimens \\
3 points bending strength \\
\hline
\end{tabular}

$181 \mathrm{~mm}$
$7.43 \%$
$2447 \mathrm{Kg} / \mathrm{m}^{3}$
$32 \mathrm{GPa}$
$25.37 \mathrm{MPa}$
$32.35 \mathrm{MPa}$
$6.31 \mathrm{MPa}$

Table 2: C 0.7 concrete characteristics

\section{Specimen manufacturing}

In order to determine the toughness of C0.7 Concrete, prismatic specimens were notched laterally (SENB). Fig. 1 shows the geometry and dimensions for used specimens $(\mathrm{S}=4 \mathrm{~W}, \mathrm{~W}=2 \mathrm{~B})$ normalized by the ASTM E399 [17, 18]. Fig. 2 offered details of the shape and geometry of notch.

Tab. 3 shows the dimensional characteristics of SENB concrete specimens.

\begin{tabular}{ccc}
\hline Notation & Description & Dimension in $\mathrm{mm}$ \\
L & Specimen length & $440 \pm 0.1$ \\
S & Distance between supports & $440 \pm 0.1$ \\
W & specimen width & $100 \pm 0.1$ \\
B & specimen thickness & $50 \pm 0.1$ \\
$\mathrm{a}_{0}$ & Notch length & $30,40,50,60$ \\
\hline
\end{tabular}

Table 3: Dimensional characteristics of SENB concrete specimens.

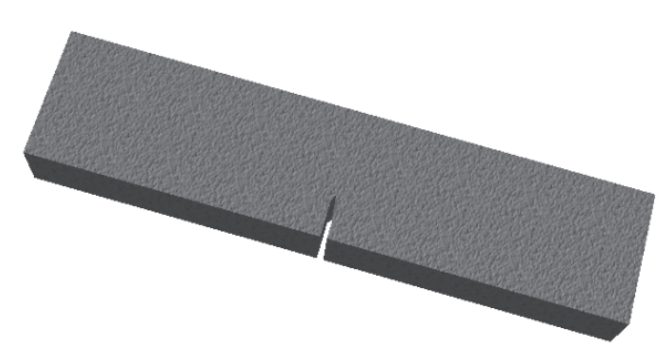

(a)

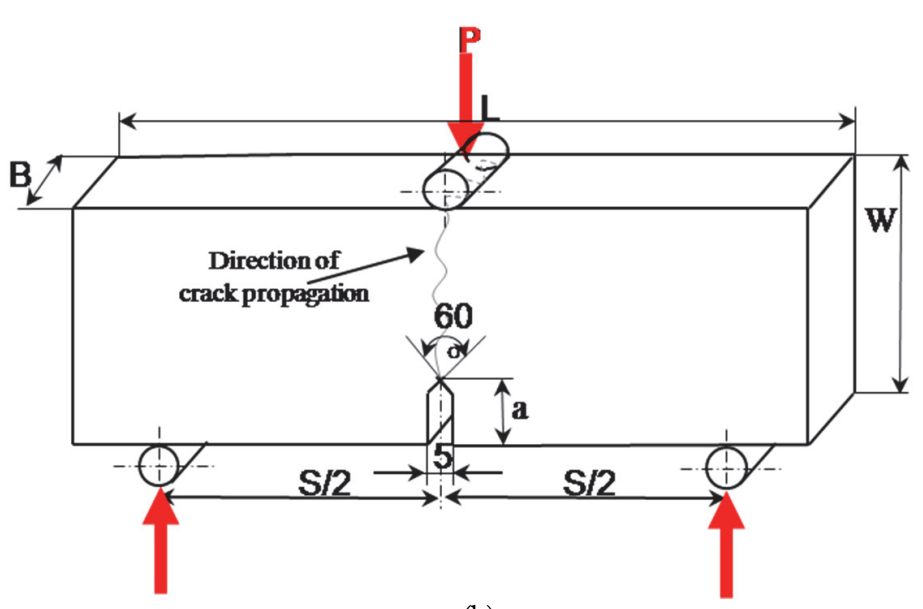

(b)

Figure 1: SENB specimen standardized by ASTM E399 (a) geometry, (b) dimensions and three point bending test principle. 


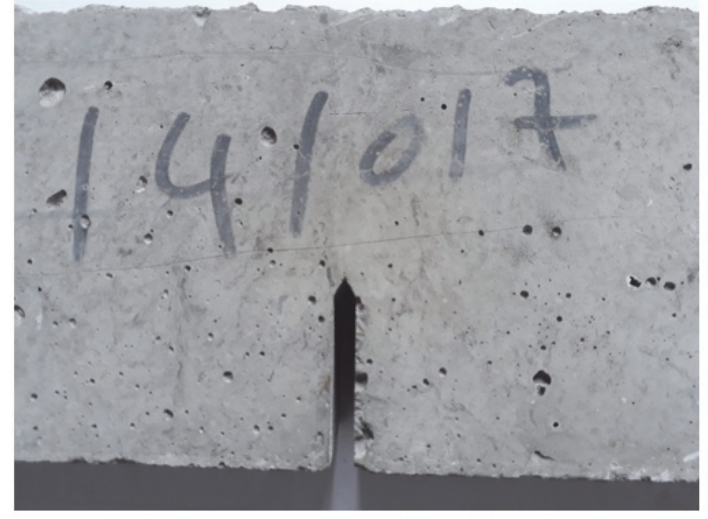

(a)

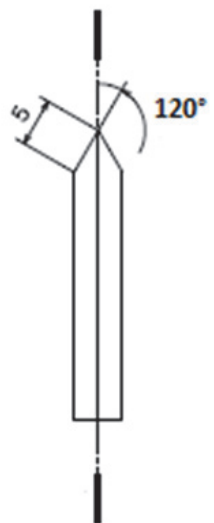

(b)

Figure 2: Notch details (a) photo of notched concrete specimen, (b) notch geometry

Sixteen SENB specimens were manufactured. Dimensionless notch length ratio $\alpha=\mathrm{a}_{0} / \mathrm{W}$ is included between 0.3 and 0.6 $(0.3<\alpha<0.6)$.For each notch length, four specimens are manufactured; the notch length incrementation is of $10 \mathrm{~mm}$. The specimens spent 28 days in a pool of water (Fig. 3) at a temperature $\left(20 \pm 2{ }^{\circ} \mathrm{C}\right)$, this 28 day period is called cure age of concrete corresponding to the time at which concrete reaches $90 \%$ of its maximum compressive strength. This strength is called the concrete characteristic strength.

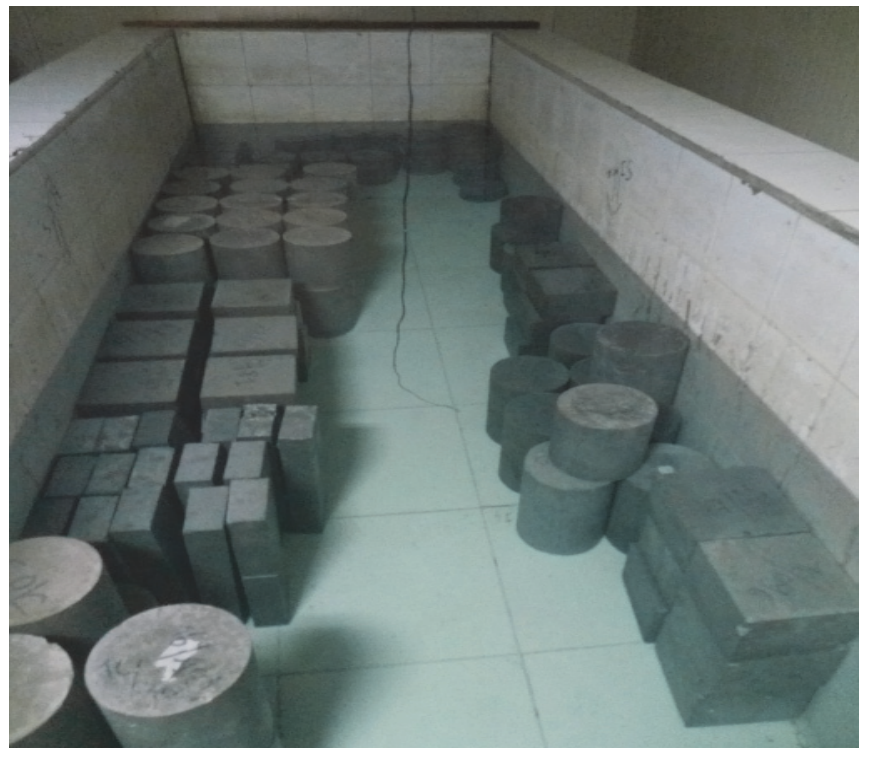

Figure 3: Conservation of concrete specimen in water pool at a temperature of $20^{\circ} \mathrm{C} \pm 2{ }^{\circ} \mathrm{C}$

\section{Features and tests assembly}

In order to measure the crack mouth opening displacement for the SENB specimens during the three-point bending test, we have used the assembly presented by Fig. 4.

With:

$1:$ applied load support

2 : reaction support

3: displacement sensor with $1 \mu \mathrm{m}$ precision used to measure the crack mouth opening displacement CMOD (Fig. 5)

4: Support-sensor with two circular magnets in its base serves to hold the sensor on a rectangular metal plate $3 \mathrm{~mm}$ thick (Fig. 6).

5: L-shaped metal plate in contact with the probe, it allows the sensor to follow the gap between the notch lips. 


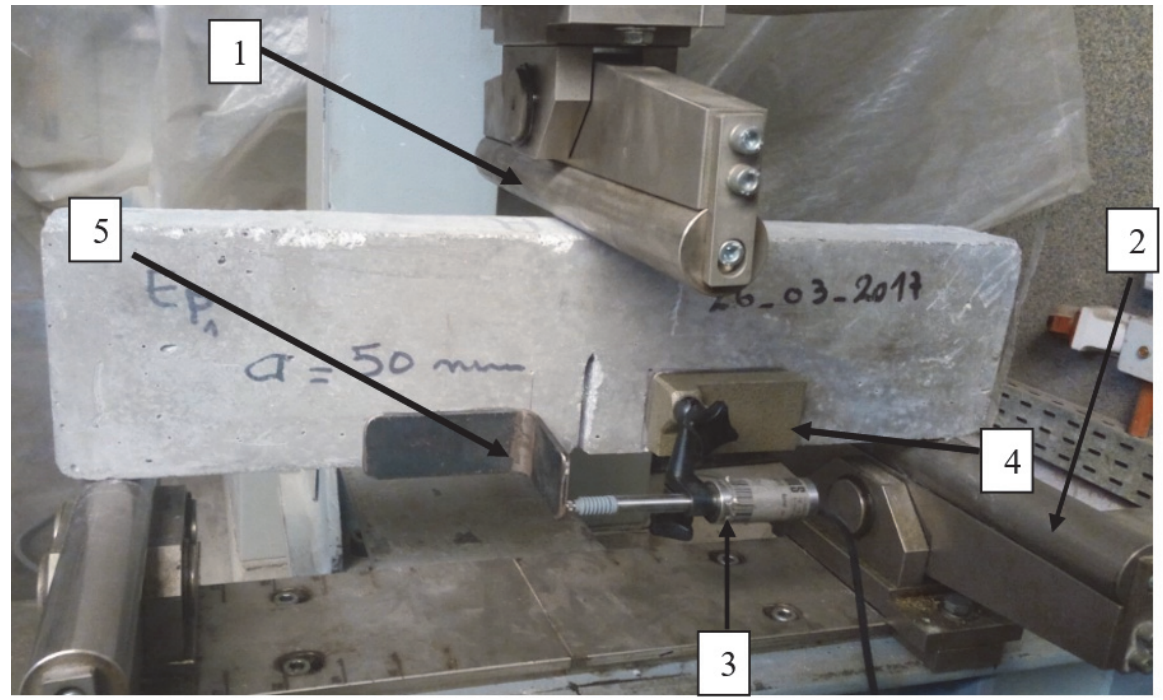

Figure 4: Test assembly for the three points bending test on SENB concrete specimens

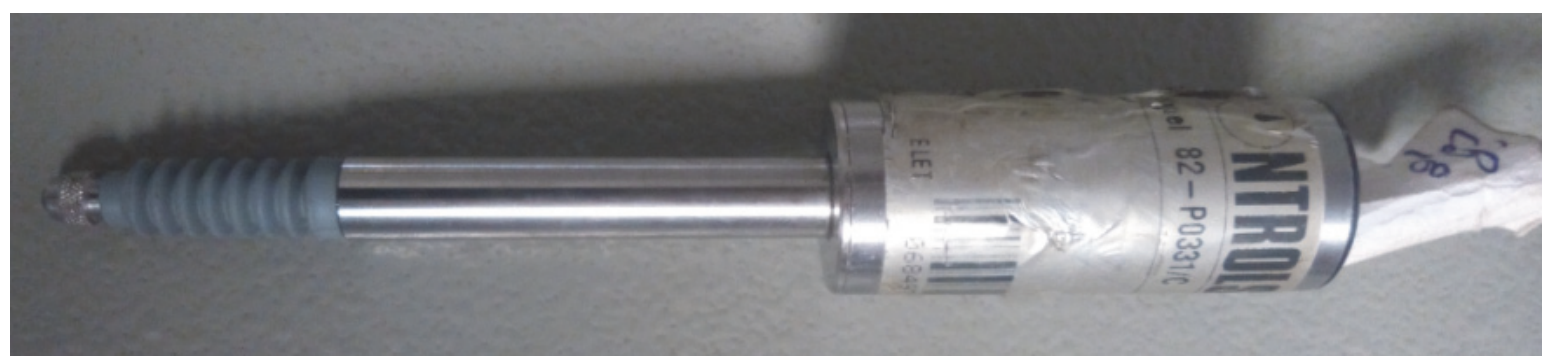

Figure 5: Displacement sensor
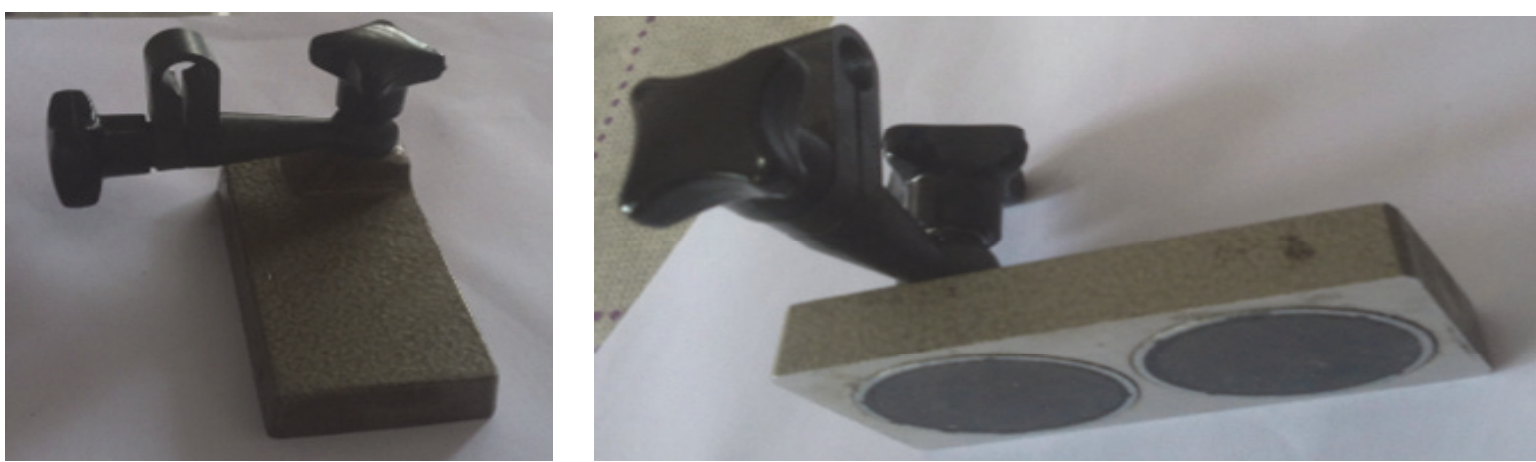

Figure 6: Sensor support

\section{Tests progress}

Three-point bending tests are performed using a uniaxial press "CONTROLS" (Fig. 7) with maximum capacity of $10 \mathrm{kN}$. The specimen surfaces must be smooth and perfectly parallel, hence the need to rectify or pre-plan them.

Before placing the test specimen in the machine, we have pasted the two metal plates (rectangular and L) with a special glue, then, we placed the magnetic displacement support -sensor on the rectangular plate. A slight compression was applied on the sensor stem before positioning it on the L-plate. To obtain a better CMOD measurement, we placed the sensor in the same basic plane of the specimen, such that the axis of the sensor rod is in the plane direction of the specimen opening notch. 
The tests were carried out with imposed displacement. The axial cylinder is moved until the sample failure, which allows to better apprehending the post-peak phase of the mechanical behavior. In order to compare the tests results for different notch lengths, tests have all been carried out with an identical displacement velocity of $30 \mu \mathrm{m} / \mathrm{min}$.

The press acquisition system has two measurement channels, and allows to recording data (load sensor and displacement sensors (LVDT)) at a sampling frequency of $5 \mathrm{~Hz}$.

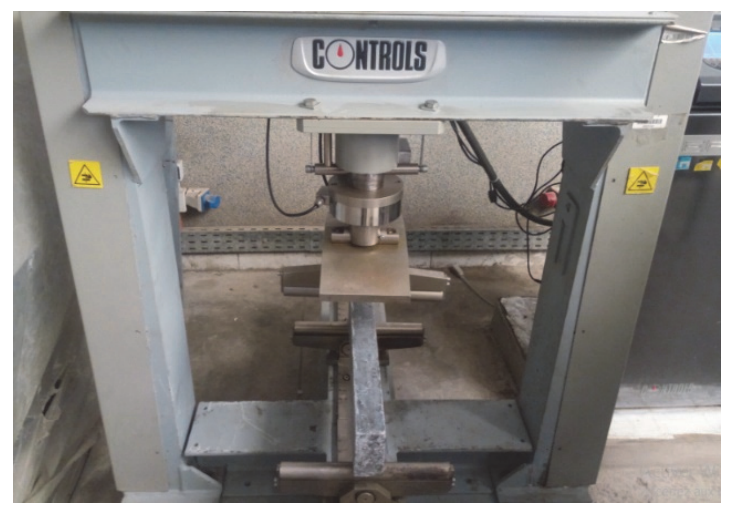

Figure 7: Uniaxial press “CONTROLS”

Determination of the stress intensity factor using the $\mathrm{R}$ curve

In the case of three-point bending test with $\mathrm{S} / \mathrm{W}=4$, we used the approach developing by Tada [19] and adopted in [12] 19, 12]. The stress intensity factor expression is given by the Eqn. (1).

$$
\begin{aligned}
& K_{I}=\sigma_{N} \sqrt{W} K(\alpha) \\
& K(\alpha)=\sqrt{\alpha} \frac{1,99-\alpha(1-\alpha)\left(2,15-3,93 \alpha+2,7 \alpha^{2}\right)}{(1+2 \alpha)(1-\alpha)^{3 / 2}}
\end{aligned}
$$

where $K(\alpha)$ is a geometric factor, $\alpha=\mathrm{a} / \mathrm{W}$ and $\sigma_{\mathrm{N}}$ is the nominal stress in the beam due to external load P and self weight of the structure which is given by :

$$
\sigma_{N}=\frac{3 S}{4 B W^{2}}\left[2 P+\frac{m g}{L} S\right]
$$

The R curve plot requires the definition, at each moment, of the propagated crack length a and the corresponding load P. In practice, the measuring of instantaneous crack length is very difficult. For this reason, effective crack length is determined by the following equations [12]:

$$
\begin{aligned}
& C M O D=\frac{6 P S}{E B W} \alpha V(\alpha) \\
& V(\alpha)=0,76+2,28 \alpha+3,87 \alpha^{2}+2,04 \alpha^{3}+\frac{0,66}{(1-\alpha)^{2}}
\end{aligned}
$$

In order to search the ratio $\alpha$ which verifies Eqn. (4), we used the dichotomy method; the principle of this method is based on the intermediate value theorem:

If $\mathrm{f}(\mathrm{a}) \cdot \mathrm{f}(\mathrm{b})<0$, then it exists $\mathrm{c} \in[\mathrm{a}, \mathrm{b}]$ such as $\mathrm{f}(\mathrm{c})=0$ 
The condition $\mathrm{f}(\mathrm{a})$. $\mathrm{f}(\mathrm{b})<0$ means that $\mathrm{f}(\mathrm{a})$ and $\mathrm{f}(\mathrm{b})$ have opposite signs (or that one of them is zero). The hypothesis of continuity is essential. To translate the dichotomy algorithm into a program, we used the VBA as a programming language. After solving Eqn. (4), we have placed the $\alpha$ found in relation (1), which allowed us to plot the R curve.

\section{RESULTS AND DICUSSIONS}

$\mathrm{T}$ ab. 4 shows all the results found for the 16 concrete specimens.

Concrete is a material with a very complex structure, for the notchs of $70 \mathrm{~mm}$, a large part of the test pieces break during demolding or in tests. It should also be noted that a remarkable dispersion has been found in the CMOD values for the same notch, which may be due to the nature and the distribution of aggregates in the material.

\begin{tabular}{|c|c|c|c|c|c|}
\hline $\begin{array}{l}\text { Specimen } \\
\text { number }\end{array}$ & $\mathrm{a}_{0}(\mathrm{~mm})$ & $\mathrm{P}(\mathrm{kN})$ & $\begin{array}{c}\mathrm{CMOD}_{\mathrm{C}} \\
(\mu \mathrm{m})\end{array}$ & $\Delta \mathrm{a}_{\mathrm{c}}(\mathrm{mm})$ & $\mathrm{K}_{\mathrm{IC}}\left(\mathrm{MPa} \cdot \mathrm{m}^{1 / 2}\right)$ \\
\hline 1 & 30 & 1.435 & 53.8 & 18 & 1.25 \\
\hline 2 & 30 & 1.601 & 56 & 30 & 1.2 \\
\hline 3 & 30 & 2.2 & 46 & 13 & 0.78 \\
\hline 4 & 30 & 1.7 & 25 & 28 & 1.5 \\
\hline \multicolumn{2}{|c|}{ average } & 1.734 & 45.200 & 20 & 1.183 \\
\hline 5 & 40 & 1.17 & 47.8 & 10 & 1.17 \\
\hline 6 & 40 & 1.572 & 34.8 & 9 & 1.01 \\
\hline 7 & 40 & 1.473 & 57 & 28 & 0.937 \\
\hline 8 & 40 & 1.3 & 33 & 16 & 0.948 \\
\hline \multicolumn{2}{|c|}{ average } & 1.38 & 43.15 & 15.8 & 1.016 \\
\hline 9 & 50 & 1.135 & 33.7 & 9 & 0.86 \\
\hline 10 & 50 & 1.174 & 39.3 & 10 & 1.16 \\
\hline 11 & 50 & 1.26 & 39 & 11 & 0.96 \\
\hline 12 & 50 & 0.938 & 52 & 8 & 1.05 \\
\hline \multicolumn{2}{|c|}{ average } & 1.13 & 41.00 & 9.5 & 1.008 \\
\hline 13 & 60 & 0.805 & 38 & 4.4 & 0.81 \\
\hline 14 & 60 & 0.601 & 30 & 6 & 0.82 \\
\hline 15 & 60 & 0.6 & 46 & 9 & 1.37 \\
\hline 16 & 60 & 0.618 & 30 & 7 & 1.03 \\
\hline \multicolumn{2}{|c|}{ average } & 0.66 & 36.00 & 6.6 & 1.008 \\
\hline
\end{tabular}

Table 4: Summary of found results

Fig. 8 show the load evolution as function of the CMOD for four different notch lengths. We note that the results obtained on these notched specimens show similar evolutions. Each of these curves begins with an elastic linear part, followed by a continuous remoteness of the real curve to the ideal line load-displacement. This non-linearity is mainly due on the one hand to a plasticization of the area in the immediate crack tip vicinity, and on the other hand to the fact that the crack tends to propagate slowly and disproportionately to the applied load until the specimen failure.

Figs. 9, 10 and 11 show respectively regrouped charge / CMOD curves, evolution of the maximum load as function of different lengths notch and the evolution of CMODc as function of different lengths notch. We can observe that the maximum load and the CMODc decrease as the length notch increases.

The crack propagation occurs in a zone strongly damaged by the plasticization. The size of this zone increases when the notch length decreases.

The CMOD technique and the numerical tools allowed us to plot the R-curves as a function of the crack propagation $\Delta \mathrm{a}$ (Fig..13), according to a preliminary analysis of these curves, we note well that the evolution of cracking goes always through three stages:

$>$ If $\Delta \mathrm{a}=0$ : the crack propagation is stopped .

$>$ If the $\Delta$ a ranges between 0 and $\Delta \mathrm{a}_{\mathrm{c}}$ we can say that the crack propagation is stable.

$>$ If the $\Delta \mathrm{a}$ is higher than $\Delta \mathrm{a}_{\mathrm{c}}$, the crack propagation is unstable 


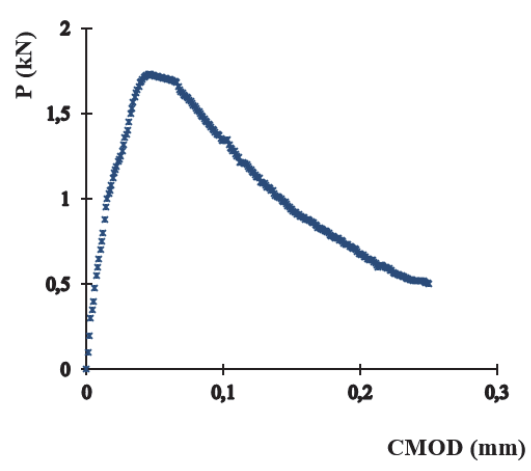

(a)

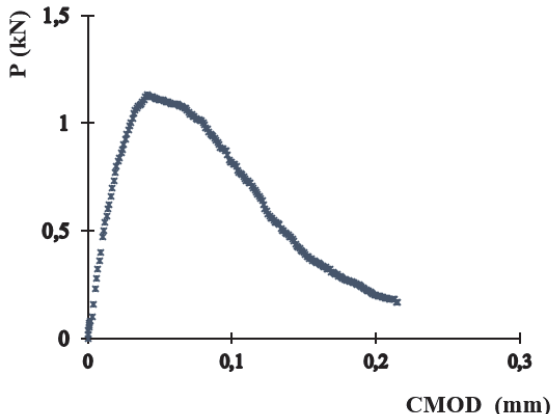

(c)

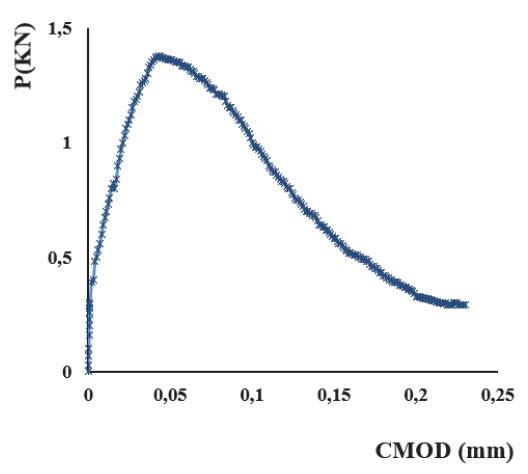

(b)

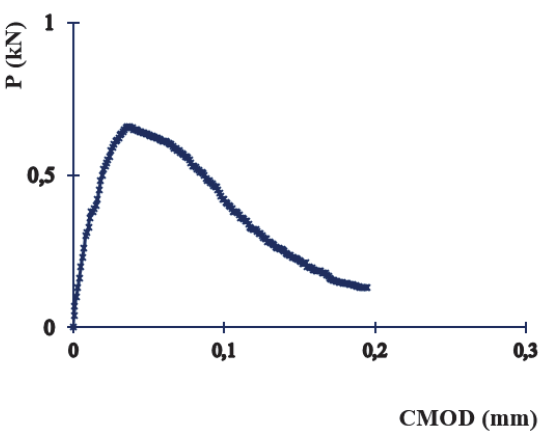

(d)

Figure 8: Evolution of the applied load as function of the CMOD for various notch lengths. a) $\left.\left.a_{0}=30 \mathrm{~mm}, \mathrm{~b}\right) \mathrm{a}_{0}=40 \mathrm{~mm}, \mathrm{c}\right) \mathrm{a}_{0}=50 \mathrm{~mm}$ and d) $a_{0}=60 \mathrm{~mm}$.

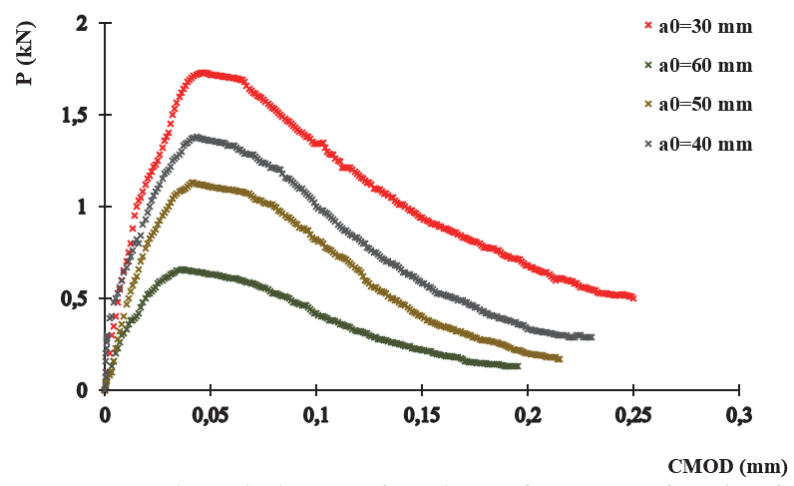

Figure 9: Load evolution as function of CMOD for the four studied notch lengths.

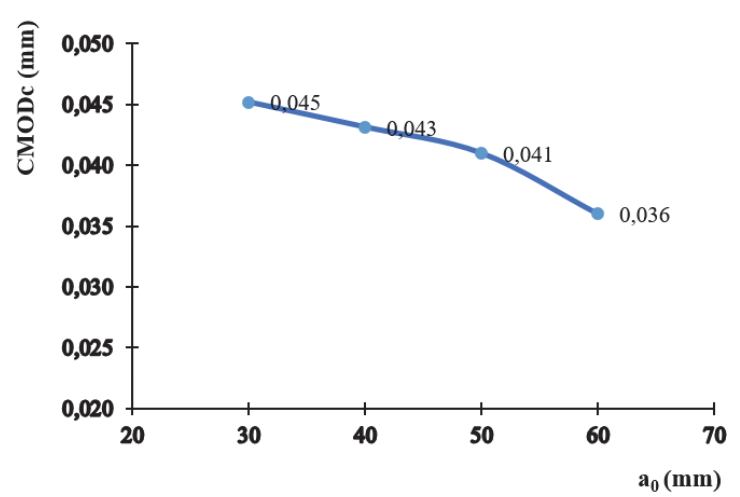

Figure 11: CMODc evolution as function of notch lengths

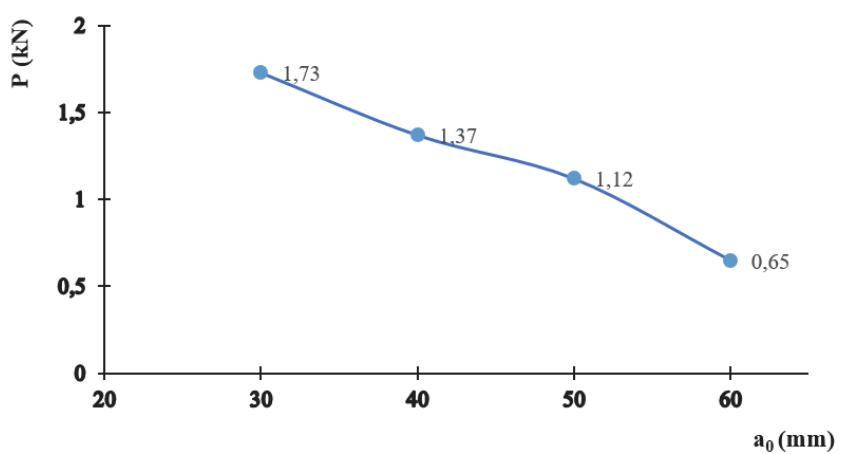

Figure 10: load evolution as function of notch lengths.

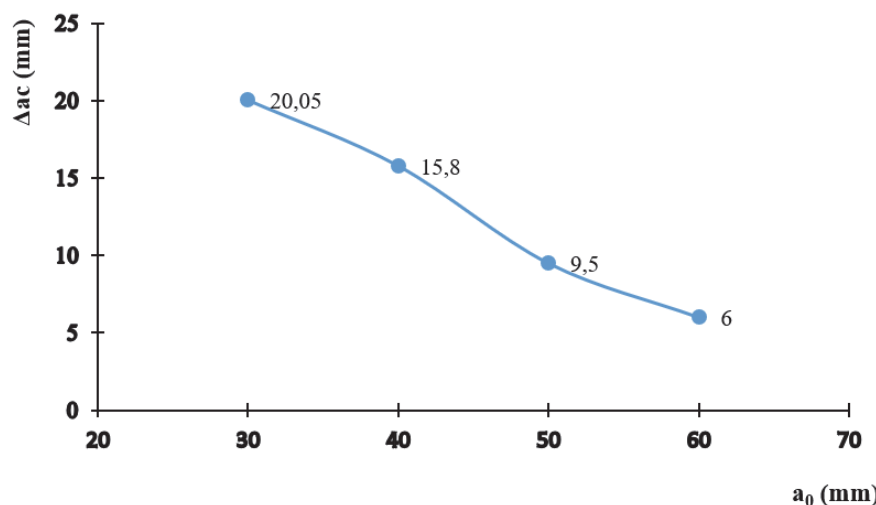

Figure 12: $\Delta$ ac evolution as function of notch length. 
Fig. 12 demonstrates the evolution of $\Delta$ ac as function of notch length. Therefore, we may observe that crack propagation decreases almost linearly and disproportionately with $\mathrm{a}_{0}$.

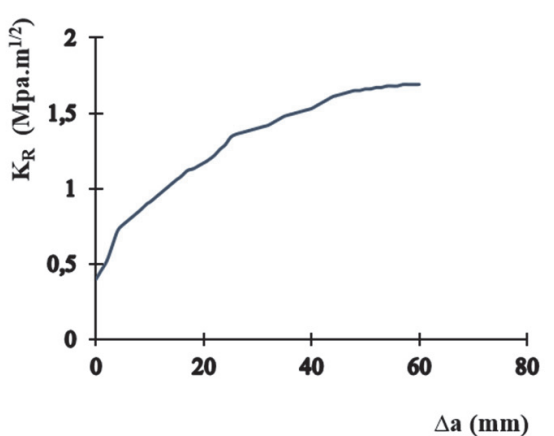

(a)

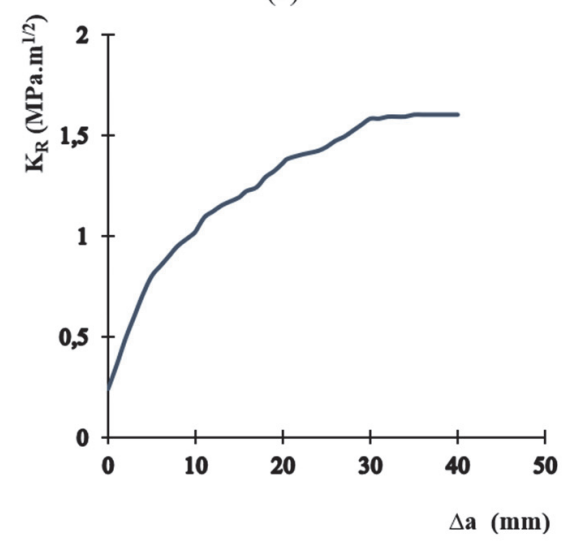

(c)

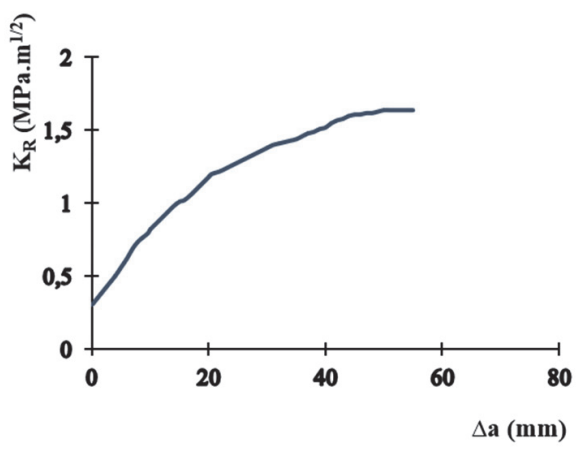

(b)

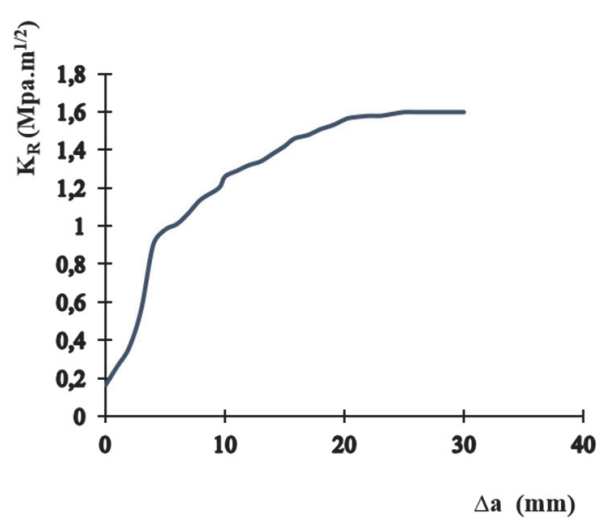

(d)

Figure 13: $K_{R}$ curve as function of $\Delta a$ for various notch lengths a) a $\left.\left.0=30 \mathrm{~mm}, \mathrm{~b}\right) \mathrm{a} 0=40 \mathrm{~mm}, \mathrm{c}\right) \mathrm{a} 0=50 \mathrm{~mm}$ and d) $\mathrm{a} 0=60 \mathrm{~mm}$

It was demonstrated that the crack propagation zone does not exceed $90 \mathrm{~mm}$ for the various initial notches a0 [20]. For our case, this is means that the specimen failure occur at $\alpha_{\max }=0.9$ (Fig. 14).
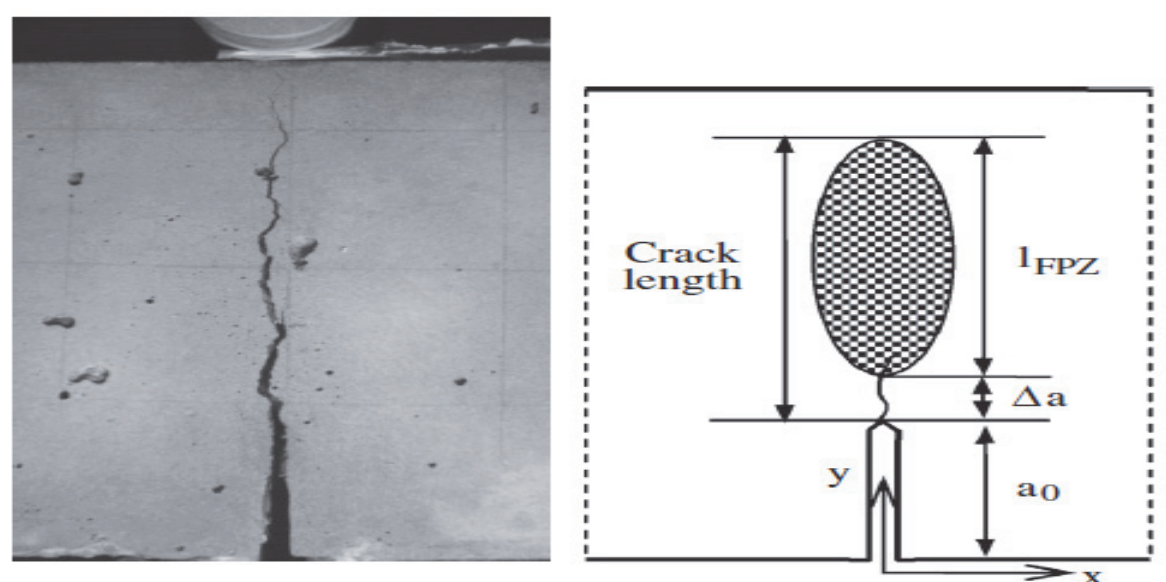

Figure 14: Representation of the crack propagation zone [15]

The critical stress intensity factor $\mathrm{K}_{\mathrm{IC}}$ corresponding to $\Delta \mathrm{a}_{\mathrm{c}}$ and $\mathrm{P}_{\max }$ is respectively equal to $1.18,1.02,1.01$, and 1.01 $\mathrm{MPa} . \mathrm{m}^{1 / 2}$ for $\mathrm{a}_{0}=30,40.50$, and $60 \mathrm{~mm}$ (Fig.. 14). From the found results, $\mathrm{K}_{\mathrm{IC}}$ has an average value of $1.05 \mathrm{MPa} . \mathrm{m}^{1 / 2}$ and a standard deviation of $0.04 \mathrm{MPa} \cdot \mathrm{m}^{1 / 2}$. 


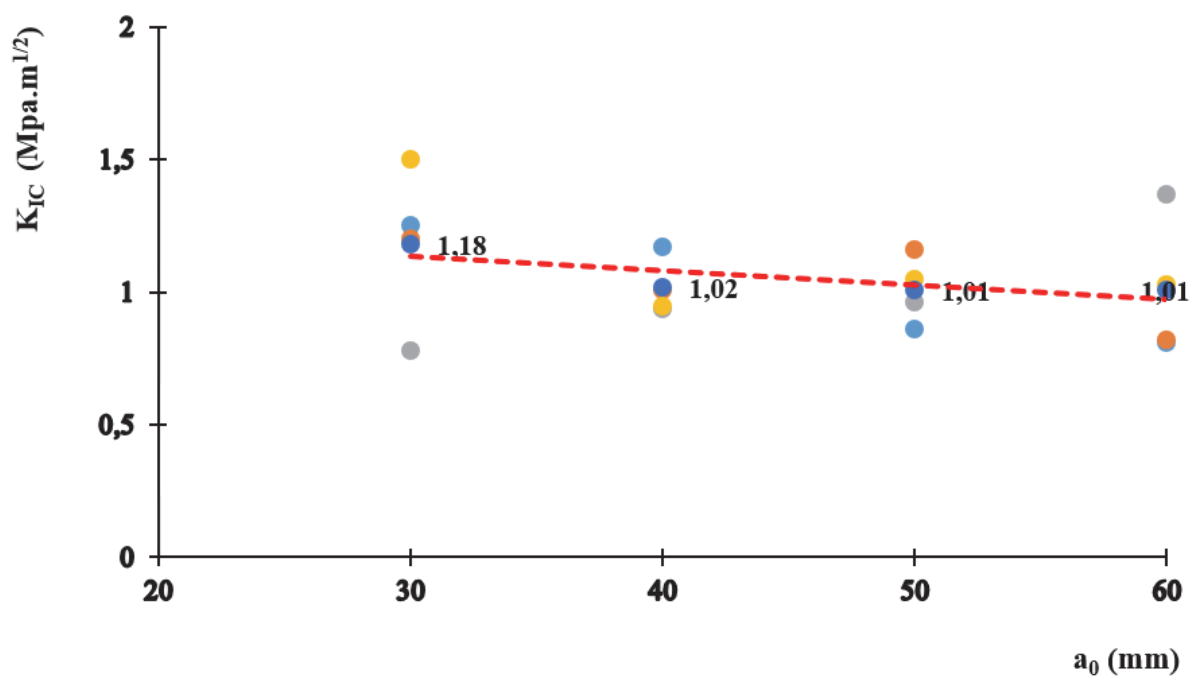

Figure 15: K $\mathrm{IC}_{\mathrm{C}}$ values as function of notch length

Fig. 16 groups the $K_{R}$ curves as function of $\Delta a$ for the different studied notch lengths. We observe that the curves are practically confounded in the unstable propagation stage, which confirms that the R-curve is a unique curve independent of the notch length.

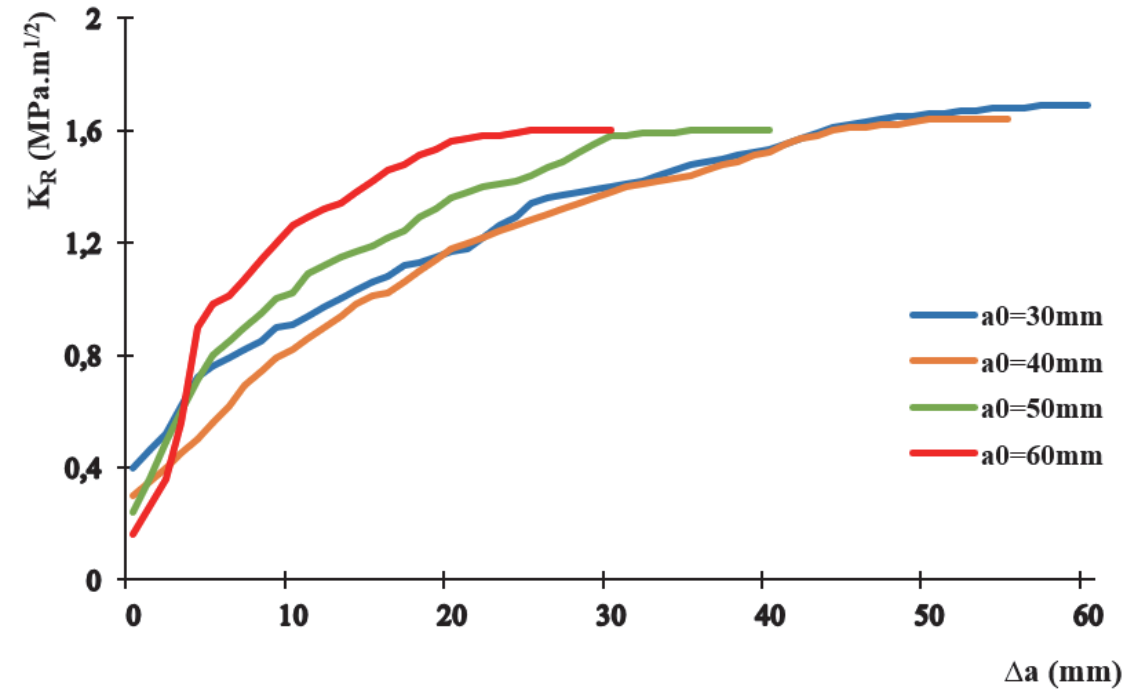

Figure 16: Regrouped KR curves as function of $\Delta \mathrm{a}$

\section{CONCLUSIONS}

$\mathrm{I}$

$\mathrm{n}$ this paper, three point bending tests were carried out on notched specimens made from $\mathrm{C} 0.7$ concrete in order to understand the mechanical behavior and the crack propagation mechanism of this quasi-brittle material. Therefore, many conclusions were made:

$\checkmark$ The crack propagates mechanism consists of two propagation stages: 1-stable propagation stage while the load is lower than $\mathrm{P}_{\max }, 2$-unstable propagation stage. The stage of unstable propagation is more important than the stable propagation stage.

$\checkmark$ The stable propagation stage decreases disproportionately to the notch length.

$\checkmark$ The opening displacement mechanism of the critical notch lips occurs in a perpendicular direction to the applied load direction; this opening displacement is even higher than the notch length is small. 
The load / CMOD curve is a useful and effective technique for determining the length propagated crack during loading, thus the R curve plot with good accuracy.

$\checkmark$ The R curves give almost the same $\mathrm{K}_{\mathrm{IC}}$ and the same maximum crack length for the various notch lengths.

$\checkmark$ Our study confirms that the $\mathrm{R}$ curve is unique and independent of the notch length, this curve represents an intrinsic parameter of concrete material, it allows to determine the critical stress intensity factor and to describe the crack evolution in quasi-fragile materials cases, so the $\mathrm{R}$ curve is a mechanical characteristic.

\section{NOMENCLATURE}

a crack length

a $\quad$ notch length

$a_{C} \quad$ critical crack length

B specimen thickness

E young's modulus

W specimen width

S distance between supports

L specimen length

SENB specimen for three-point bending

CMOD crack mouth opening displacement

CMODc critical crack mouth opening displacement

$\mathrm{P} \quad$ applied load

$\mathrm{P}_{\max } \quad$ maximal load

$\begin{array}{ll}\sigma_{\mathrm{N}} & \text { nominal stress } \\ \mathrm{K}_{\mathrm{R}} & \text { R-curve in function of stress intensity factor fracture } \\ \mathrm{FPZ} & \text { process zone } \\ \Delta \mathrm{a} & \text { crack extension } \\ \Delta \mathrm{a}_{\mathrm{c}} & \text { critical crack extension } \\ \Delta \mathrm{a}_{\max } & \text { maximal crack extension } \\ \alpha_{0} & \alpha_{0}=\mathrm{a}_{0} / \mathrm{W} \text { initial crack length ratio } \\ \alpha & \alpha=\left(\mathrm{a}_{0}+\Delta \mathrm{a}\right) / \mathrm{W} \text { crack extension ratio } \\ \alpha_{\mathrm{c}} & \alpha_{\mathrm{c}}=\left(\mathrm{a}_{0}+\Delta \mathrm{a}_{\mathrm{c}}\right) / \mathrm{W} \text { critical crack extension ratio } \\ \alpha_{\max } & \alpha_{\max }=\left(\mathrm{a}_{0}+\Delta \mathrm{a}_{\max }\right) / \mathrm{W} \text { maximal crack extension ratio } \\ \mathrm{K}_{\mathrm{I}} & \text { stress intensity factor in mode I } \\ \mathrm{K}_{\mathrm{IC}} & \text { critical stress intensity factor in mode I }\end{array}$

$\sigma_{\mathrm{N}} \quad$ nominal stress

crack extension

critical crack extension

maximal crack extension

ngth ratio

$\alpha=\left(\mathrm{a}_{0}+\Delta \mathrm{a}\right) / \mathrm{W}$ crack extension ratio

$\alpha_{c}=\left(\mathrm{a}_{0}+\Delta \mathrm{a}_{\mathrm{c}}\right) / \mathrm{W}$ critical crack extension ratio

$\alpha_{\max }=\left(\mathrm{a}_{0}+\Delta \mathrm{a}_{\max }\right) / \mathrm{W}$ maximal
stress intensity factor in mode

critical stress intensity factor in mode I

\section{REFERENCES}

[1] Sanz, G. (1974). La rupture des aciers - Première partie : la rupture fragile - Collection IRSID-OTUA.

[2] Funari, M.F., Greco, F., Lonetti, P., Luciano, R., Penna, R. (2018) An interface approach based on moving mesh and cohesive modeling in Z-pinned composite laminates. Composites Part B: Engineering; 135, pp. 207-217, DOI: $10.1016 /$ j.compositesb.2017.10.018.

[3] Funari, M.F., Lonetti, P., Spadea, S. (2019) A crack growth strategy based on moving mesh method and fracture mechanics. Theoretical and Applied Fracture Mechanics; 102, pp. 103-115, DOI: 10.1016/j.tafmec.2019.03.007.

[4] Funari, M.F., Greco, F., Lonetti, P. (2019) A numerical model based on ALE formulation to predict crack propagation in sandwich structures. Frattura ed Integrità Strutturale, 47, pp. 277-293. DOI: 10.3221/igf-esis.47.21.

[5] Broek, D. (1984). Elementary engineering fracture mechanics. Boston: Kluwer Academic Publisher

[6] Broek, D. (1988). The practical use of fracture mechanics. Boston: Kluwer Academic Publisher

[7] Zhu, X.-K., Joyce, J.A. (2012) Review of fracture toughness (G, K, J, CTOD, CTOA) testing and standardization. Engng. Fract. Mech. 85, pp. 1-46. , DOI: 10.1016/j.engfracmech.2012.02.001.

[8] Kailer, A. Marc, S. (2016). On the feasibility of the Chevron Notch Beam method to measure fracture toughness of fine-grained zirconia ceramics. 32(10), pp. 1256-1262, DOI: 10.1016/j.dental.2016.07.011.

[9] Graziani, L. (2014). Measurement of R-curve in clay brick blocks using optical measuring technique, Engineering fracture mechanics, 121, pp. 1-10. DOI: 10.1016/j.engfracmech.2014.04.007.

[10] Yanhua, Z., Jianmei, C., Hangab, H.G. (2015). A three-parameter R-curve of concrete-like quasi-brittle materials, Construction and Building Materials. 78(1), pp. 243-249. DOI: 10.1016/j.conbuildmat.2015.01.029.

[11] Alam, M.R. (2010). Fracture toughness of plain concrete specimens made with industry-brunt brick aggregates. 38(1), pp. 81-94.

[12] Kumar, S., Rajendra, K.C. (2015). Further observations on the three-parameter R-curve of concrete-like quasi-brittle materials, Construction and Building Materials, 93, pp. 857-868. DOI: 10.1016/j.conbuildmat.2015.05.079.

[13] Ferreiraa, L.E.T. Bittencourt, T.N. Sousa, J..L.A.O . Gettu.R. (2002). R-curve behavior in notched beam tests of rocks, Engineering Fracture Mechanics.69(17): 1845-1852 , DOI: 10.1016/S0013-7944(02)00064-4

[14] Jisun, C., Goangseup, Z., Shinichi, H., Kohei, Y., Soye, K. (2014). Influence of fiber reinforcement on strength and toughness of all-lightweight concrete, Construction and Building Materials. 69, pp. 381-389

DOI: $10.1016 /$ j.conbuildmat.2014.07.074. 
[15] Shilang, X., Reinhardt, H.W. (1999) Determination of Double-K Criterion for Crack Propagation in Quasi-Brittle Materials, part I: experimental investigation of crack propagation, International Journal of Fracture, 98(2), pp. 111-149 DOI: 10.1023/A:1018668929989

[16] Shilang, X., Reinhardt, H.W. (1999) Determination of Double-K Criterion for Crack Propagation in Quasi-Brittle Materials, part II: Analytical Evaluating and Practical Measuring Methods for Three-Point Bending Notched Beams, International Journal of Fracture, 98(2), pp. 151-177. DOI: 10.1023/A:1018740728458

[17] ASTM international standard E399-72. Standard method of test for plane strain fracture toughness of metallic materials. (1972).

[18] ASTM international standard E399-06. Standard test method for linear elastic method plane strain fracture toughness test KIc of metallic materials. (2006), pp. 1-32.

[19] Tada, H., Paris, P.C., Irwin, G., (1985). The stress analysis of cracks handbook. St. Louis, MO, USA: Paris Productions Incorporated;

[20] Chen, H.H., Su, R.K.L. (2013) .Tension softening curves of plain concrete, Construction and Building Materials 44, pp. 440-451, DOI: 10.1016/j.conbuildmat.2013.03.040 